\title{
Interannual Variability of Thermal Conditions in the Extratropical Zone of the South Pacific at the Turn of the XX-XXI Centuries
}

\author{
I. D. Rostov ${ }^{凶}$, E. V. Dmitrieva, N. I. Rudykh \\ V. I. Il'ichev Pacific Oceanological Institute, Far Eastern Branch of Russian Academy of Sciences, \\ Vladivostok, Russian Federation \\ rostov@poi.dvo.ru
}

Purpose. The aim of the study consists in identifying the spatial-temporal features of interannual changes in the surface air temperature $T_{a}$, the sea surface temperature (SST) and the upper 1000-meter water layer temperature $T_{w}$ in the extratropical zone of the South Pacific Ocean over the past four decades, which are manifested as a result of the planetary changes and a shift in the climatic regime at the turn of the XX-XXI centuries. Besides, the revealed features' trends and their possible cause-andeffect relationships with the processes in the atmosphere and on the ocean surface are planned to be assessed.

Methods and Results. Based on the Global Meteorological Network and Reanalysis data (NOAA), regional features and trends of the water and air temperature interannual fluctuations, and their relation to variations in the pressure and wind fields, intensity of the atmosphere action centers (AAC) and climatic indices (CI) over the past 4 decades have been determined. Applied were the methods of the cluster, correlation and regression analysis, as well as the apparatus of empirical orthogonal functions (EOF). The positive trends in changes of the $T_{a}$ and SST fields are manifested mainly in the northwestern part of the region, where they are statistically significant and reach their maximum $0.4-0.6^{\circ} \mathrm{C}$ over 10 years in the Tasman Sea region and to the northeast of New Zealand. The water areas with minimal, negative or insignificant values of the air and water temperature trends are located on the southern and eastern peripheries of the water area under study - in the areas of influence of cold currents. Over the entire investigated water area, the trends in the mean annual SST and $T_{a}$ were $\sim 0.04-0.06^{\circ} \mathrm{C} / 10$ years that are $2-3$ times less than those in the subarctic region of the North Pacific Ocean. The features of spatial-temporal variability of the water temperature trends at different horizons differ significantly from the characteristics of the SST trends. The trends' spatial distribution is already transformed within the upper 200-m layer; and deeper, maximums of this value are observed in the southeastern part of the water area.

Conclusions. The results obtained made it possible to characterize the degree of heterogeneity of response of the atmosphere surface layer, SST and vertical distribution of $T_{w}$ in the extratropical zone of the South Pacific to the ongoing global changes, to identify the isolated areas, to estimate quantitatively the warming rate in these water areas, and to compare these estimates with those of the other regions in the Pacific Ocean. It is shown that the individual phases of alternation of the warm and cold periods in the interannual temperature variation are consistent with the changes of the regional CI and the AAC state; this fact emphasizes the inhomogeneous nature of these processes in space and time.

Keywords: South Pacific, extratropical zone, current climatic changes, regional features, water and air temperature, warming and cooling trends, climatic parameters, correlations

Acknowledgments: the work was carried out within the framework of the state task of POI FEB RAS on theme No. 0211-2021-0008, state registration number is 121021700346-7. The authors are thankful to the program developers for the opportunity to use the climatic data posted on the NOAA sites.

For citation: Rostov, I.D., Dmitrieva, E.V. and Rudykh, N.I., 2021. Interannual Variability of Thermal Conditions in the Extratropical Zone of the South Pacific at the Turn of the XX-XXI Centuries. Physical Oceanography, [e-journal] 28(6), pp. 612-631. doi:10.22449/1573-160X-2021-6-612-631

DOI: 10.22449/1573-160X-2021-6-612-631

(C) I. D. Rostov, E. V. Dmitrieva, N. I. Rudykh, 2021

(C) Physical Oceanography, 2021 


\section{Introduction}

In the conditions of increasing greenhouse gas emissions into the atmosphere, the global warming process goes on. It is characterized by spatio-temporal heterogeneity and is accompanied by a restructuring of atmospheric processes. This leads to a redistribution of excess energy of the greenhouse effect between the atmosphere and the ocean and the formation of vast areas of anomalies of climatic parameters and an increase in the impact of extreme weather events [1]. This process negatively affects both the infrastructure and the ecological state of various regions, including the activities of several sectors of the economy. The oceans absorb much of the excess heat from the atmosphere. Over the past 50 years, the oceans have absorbed about $90 \%$ of the anthropogenic heat entering the climate system. The rest of the heat goes to melting ice and glaciers, as well as heating the land surface and atmosphere [2].

According to review [3], in 2019 the global average sea surface temperature (SST) was $0.38-0.40^{\circ} \mathrm{C}$ higher than the average one for the $1981-2010$ base period, and this year was one of the three warmest years for the entire history of observations. For 20 years from the beginning of this century, the linear trend of the average annual SST for various climatic arrays was estimated at $0.14-0.17^{\circ} \mathrm{C} / 10$ years. At the same time, the largest trend value $\left(0.29^{\circ} \mathrm{C} / 10\right.$ years $)$ was noted in the North Pacific Ocean $\left(30-60^{\circ} \mathrm{N}\right)$, and the smallest $\left(0.13^{\circ} \mathrm{C} / 10\right.$ years $)$ - in the Southern Ocean $\left(30-60^{\circ} \mathrm{S}\right)$ [3].

Heat absorption and temperature increase on the sea surface is accompanied by its redistribution horizontally and vertically and an increase in the heat content of the World Ocean waters in the layer up to $2000 \mathrm{~m}$ and below to the highest values in 2019-2020 over the past decades [1, 4]. At that, 30\% of warming occurs at a depth below $700 \mathrm{~m}$ [2]. Quantitative characteristics, temporal variability trends and other features of this process differ from region to region $[5,6]$ and are closely related to ongoing climatic changes [7], including interactions between different oceanic basins [8]. It is noted that the increase in global heat content in the ocean is mainly due to regional warming in the middle latitudes of the Southern Hemisphere, where warming takes place at all depths, and $\sim 80 \%$ is concentrated to the south of $30^{\circ} \mathrm{S}$ $[6,9]$.

In the southern Pacific Ocean, as well as in its northern part, the climatic regime shift of the late 1970s [1,5] is expressed in the characteristics of interannual fluctuations of large-scale anomalies of meteorological and oceanographic parameters, the state of atmosphere action centers (AAC), indicators of heat and energy exchange between the ocean and the atmosphere and is consistent with the long-term migration of the Antarctic Circumpolar Current (ACC) [9-11]. However, the overall warming trends and their regional features are considerably different in each of these geographic regions.

Regional features of the weather and climatic conditions of the southern Pacific Ocean are largely determined by the interaction of three main baric formations - the Australian minimum (AVM), the South Pacific Maximum (SPMA) and the Minimum (SPMI), which are permanent or seasonal AACs, as well as the influence of other AACs such as the Asian Depression (AD), Indian Ocean Minimum and Antarctic Maximum (AM) [12]. The relationship between the AAC characteristics is traced not only with the features of the thermal PHYSICAL OCEANOGRAPHY VOL. 28 ISS. 6 (2021) 
conditions of the region, but also with variations in the surface temperature of the entire Southern Hemisphere and key climatic modes of interannual and interdecadal fluctuations in atmospheric pressure and temperature [12, 13].

The baric field structure in the southern Pacific Ocean on a planetary scale is represented by two main forms - the subantarctic depression encircling Antarctica and the subtropical high-pressure belt. The anticyclonic region in the subtropics and the cyclonic one in the subantarctic are separated by a polar atmospheric front, the position of which approximately corresponds to the subantarctic hydrological front $[13,14]$. In the interannual variability of atmospheric pressure anomalies in the Southern Hemisphere, there are two main modes of oscillations - the southern cilcular mode (SAM) and the equatorial-tropical mode (ETM): El Niño - Southern Oscillation (ENSO), characterized by synchronous antiphase oscillations between moderate and high latitudes $[13,15]$. The southern circular mode reflects the zoning of air mass transfer at temperate and high latitudes as a basic characteristic of atmospheric processes and manifests in many atmospheric variables, including geopotential altitude, sea level pressure, air temperature and sea ice variability [16]. An indicator of the increase or decrease in the zonal transport intensity is the Antarctic Oscillation Index (AAO), defined as the difference between the average values of surface atmospheric pressure at $40^{\circ} \mathrm{S}$ and $65^{\circ} \mathrm{S}$. [17].

The equatorial-tropical mode is characterized by the Southern Oscillation Index (SOI [18]) and other indicators of El Niño events [13, 19]). Interannual variations in the $\mathrm{AAO}$ and SOI indices, atmospheric pressure fields, turbulent heat fluxes on the sea surface, and SST anomalies in the extratropical zone of the South Pacific are interrelated. Character of these relations changes depending on the season, both in their structure and in amplitude [15, 20-22]. In the climatic system of high southern latitudes, there is quasi-ten-year variability, especially in the SAM and ETM activity, the Interdecadal Pacific Oscillation (IPO), as well as in the SST oscillations $[23,24]$. Over the past several decades, AAO has shown an upward trend [11] with increasing pressure at sea level in mid-latitudes. Corresponding changes in atmospheric circulation include an increase in the flow of the East Australian Current (EAC) through the Tasman Sea and cause warming in the sea water column, which is most significant in the entire Southern Hemisphere [6, 25]. At the same time, an increase in the activity of tropical cyclones spreading to the southeast from the coast of Australia, where the highest values of sensible and latent heat fluxes into the atmosphere were observed, is noted [26]. This ocean region is one of the main heat accumulators in the southern Pacific Ocean, and the conditions for its accumulation are associated with increased wind convergence and La Niña events [7].

The present study is aimed at identifying the spatial-temporal features of interannual changes in the surface air temperature $T_{a}$, the sea surface temperature (SST) and the upper 1000-meter water layer temperature $T_{w}$ in the extratropical zone of the South Pacific Ocean over the past four decades, which are manifested as a result of the planetary changes and a shift in the climatic regime at the turn of the 20-21 $1^{\text {st }}$ centuries. The extratropical zone [20] of the South Pacific Ocean between $30^{\circ} \mathrm{S}$ and $60^{\circ} \mathrm{S}$ with the adjacent latitudinal belt of the Southern Ocean up to $65^{\circ} \mathrm{S}$ is considered. The southern boundary of this area approximately corresponds to the position of the drifting ice distribution boundary during $>70 \%$ 
of the time of the year [20,27]. As a result of continuous improvement of observation methods and systems of assimilation of meteorological, oceanographic and satellite data, the study area is sufficiently fully provided with information resources of various climatic arrays for the period under consideration [28-30]. At the same time, when using the data, some limitations regarding the representativeness of the SST, $T_{a}$, atmospheric pressure and $T_{w}$ in situ reanalysis data in the high latitude regions of the Southern Hemisphere [11, 13, 31], especially with sea ice, should be taken into account [32].

\section{Data and Methods}

The monitored homogeneous data sets of air temperature $\left(T_{a}\right)$ observations at 25 weather stations of the global climate network GHCN-M (V3) NOAA (https://www.ncdc.noaa.gov/ghcnm/v3.php) for 1978-2020, grid reanalysis data $\left(T_{a}\right.$ - NCEP/NCAR Reanalysis-1), fields of pressure, wind and heat fluxes on the sea surface, as well as climatic indices (CI) taking into account the seasonality of their action: PDO, AMO, AAO, SOI, PTW, NP , IPO, PNA, EP/NP were used [33]. The considered CIs have a clear geographic reference and a certain physical interpretation (https://climatedataguide.ucar.edu/climate-data). The listed data was obtained from the NOAA websites (https://www.esrl.noaa.gov/psd/), NOAA/NCEI/CPC (https://www.nodc.noaa.gov/) and (https://www.cpc.ncep.noaa.gov/).

To analyze the interannual fluctuations of water temperature, the data of the optimal SST-NOAA OI SST V2 interpolation for 1982-2020 from https://www.esrl.noaa.gov/psd/ and data on the potential water temperature at different horizons $\left(T_{w}\right)$ of the GODAS oceanographic data assimilation system (https://www.esrl.noaa.gov/psd/data/gridded/data.godas.html) for 1980-2020 was used. To determine the correspondence of the GODAS grid data to the nature of the problems being solved, this data on sample sections was compared with the data of surveys carried out in different years in the South Pacific Ocean during the WOCE program [34] (https://cchdo.ucsd.edu/search?bbox=120,-60,-75.65), as well as materials from the constantly updated WOD 2018 database [28], available at https://www.ncei.noaa.gov/products/world-ocean-database. Further, the work used GODAS data only for 2005-2020 period. At this time, in the study area, the share of information entering the system from the observation network of free drifting/diving floats significantly increased: from less than 6,000 profiles in 2000-2005, distributed extremely irregularly over the water area, to 280.5 thousand profiles in 2005-2020 in the conditions of its full coverage.

A unified methodology of statistical processing of the used data [33], supplemented by regression analysis of the set of climatic variables was applied. The conditionally warm (November - March) and conditionally cold (June September) seasons (periods) of the Southern Hemisphere were identified. Trends were estimated for a time series that includes the average annual values of the variables and their anomalies $(\Delta)$, defined as the deviation from the average for all years of the 30-year period of 1984-2013.

The 95\% significance level of time series trends was assessed by the Student's test using effective degrees of freedom [29], and the determination of the significance of the correlation and regression coefficients for series with different degrees of freedom was assessed according to [35]. 
Using the SST data by the cluster analysis methods for three main components* in the extratropical zone of the South Pacific, the following four isolated regions were identified - northwestern (NW), southwestern (SW), central (C), and eastern (E) (Fig. 1,b). Subsequently, by simple averaging of grid data, the long-term variation of water and air temperatures within the boundaries of each region was calculated.
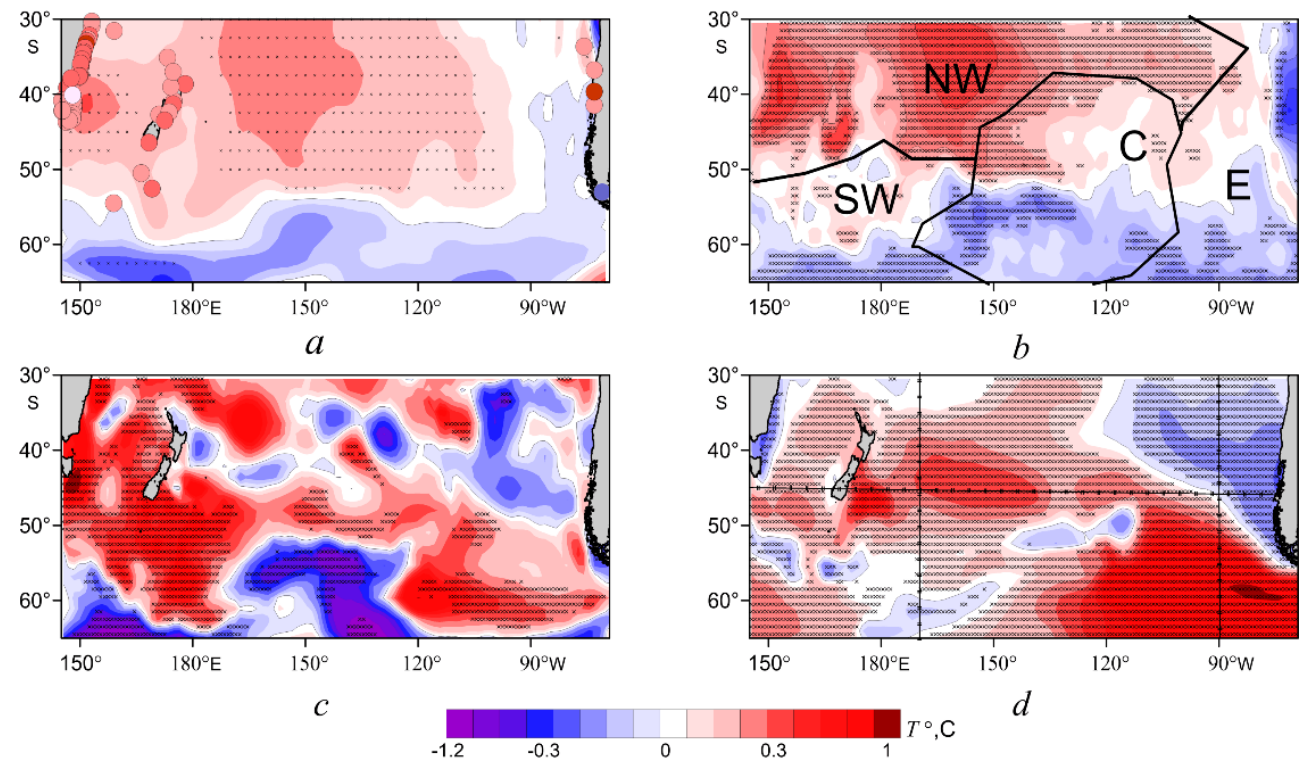

F i g. 1. Values of the trends $\left({ }^{\circ} \mathrm{C} / 10\right.$ years) of the $T_{a}(a), S S T(b)$ and $T_{w}$ annual average values at the levels $150 \mathrm{~m}(c)$ and $950 \mathrm{~m}(d)$ based on the observations at meteorological stations, reanalysis and GODAS. Locations of the meteorological stations (a), selected areas $(b)$ and individual sections (d) are shown. Here and below, crosses denote the grid nodes at which the estimates are statistically significant at the $95 \%$ level

\section{Features of spatial and interannual variability of the air temperature and SST}

In the near-water layer of the atmosphere and on the sea surface, warming trends are expressed in positive trends in the $T_{a}$ and SST fields, mainly in the northwest of the region (NW region), where they reached $0.4-0.6^{\circ} \mathrm{C} / 10$ years and were statistically significant in most of the water area (Fig. 1, $a, b$ ). The southern boundary of this area corresponds to the subtropical front position [14]. Fast warming in these areas is accompanied by the pumping and accumulation of heat in the upper layer of the sea, which leads to an increase in the heat content and steric level due to the thermal expansion of the water column [7]. The warming, which is abnormal for the entire Southern Hemisphere, in the Tasman Sea region may be associated with the intensification of the SAM circulation,

* Ding, C. and He, X., 2004. K-means Clustering via Principal Component Analysis. In: Association for Computing Machinery, 2004. Proceedings of the Twenty-first International Conference on Machine Learning (ICML '04). Banff, Alberta, Canada: ACM Press, 29. doi:10.1145/1015330.1015408 
the peculiarities of its interaction with the ETM and the EAC strengthening was noted in previous years [25,36]. Another maximum of the $T_{a}$ and SST trends centered at $35^{\circ} \mathrm{N}$ and $160^{\circ} \mathrm{W}$ is due to the strengthening of the equatorial trade winds over the Pacific Ocean and an increase in the activity of tropical cyclones in the northwestern part of the considered water area [26]. Areas with minimal and negative values of the $T_{a}$ and SST trends are located on the southern and eastern periphery of the water area under study - in the area of influence of cold waters of ACC, South Chilean and Peruvian currents. Their minimum values are limited in the north by the position of the southern polar and subantarctic frontal zones [14, 20]. Features of the spatio-temporal variability of water temperature trends at different horizons (Fig. 1, $c, e$ ) differ significantly from the characteristics of the SST trends and will be discussed below. Note that a noticeable transformation of the spatial distribution of trends occurs already within the upper 200-m layer, and deeper. The maximum values of this magnitude are observed in the southeastern part of the water area. In this area, the surface Antarctic waters of the circumpolar frontal region are discharged into the underlying layers through an "exchange window" $10^{\circ}$ wide located to the east of $90^{\circ} \mathrm{W}$ [37]. As a result of strong western winds, increased heat losses on the surface and subduction, the Antarctic modal and subarctic intermediate waters turn out to be warmer, saltier and denser [38, 39]. Since 1979, near the coast of Antarctica, in contrast to the Arctic region, there has been a moderate and statistically significant increase in the ice cover area [27]. At the same time, the observational data at individual meteorological stations in the south of Argentina and on the Antarctic coast show negative trends in $T_{a}$. Table 1 shows quantitative estimates of the trends in the ongoing changes in $T_{a}$ and SST on average for regions per year and in individual seasons.

In most of the water area, the values of the $T_{a}$ trends in the cold season were slightly higher than in the warm one, and the SST trends - vice versa. Estimates of the dispersion of the average annual air temperature exceeded the dispersion of the water temperature. In general, over the past four decades in the NW region, the average annual temperatures $T_{a}$ and SST have increased on average by 0.7$0.8^{\circ} \mathrm{C}$, while in other regions they have hardly changed. In these areas, the lowest values of the correlation coefficient of fluctuations of interannual values of water and air temperatures were noted. Trends of the average annual $T_{a}$ at meteorological stations located on the coasts of Australia, Tasmania, New Zealand and South America slightly exceeded the corresponding values in the waters of adjacent regions (Fig. 1, a). For the entire water area under study, the trends of the average annual SST and $T_{a}$ were $\sim 0.04-0.06^{\circ} \mathrm{C} / 10$ years, which is $2-3$ times less than for the subarctic region of the northern Pacific Ocean [40, 41].

Interannual changes in the mean annual SST, $T_{a}$ and accumulated anomalies within each region are identical and differ noticeably among themselves in the amplitude, synchronism of fluctuations and general trends of the process (Fig. 2). 
Interannual changes of the air temperature (1977-2020) and SST (1982-2020) anomalies in the identified areas

\begin{tabular}{|c|c|c|c|c|c|c|c|}
\hline Area & Parameter & $\sigma^{2}$ & $b$ & tr & $b_{w}$ & $b_{c}$ & $R$ \\
\hline \multirow{2}{*}{ NW } & $T_{a}$ & 0.13 & 0.17 & 0.7 & 0.13 & 0.20 & \multirow{2}{*}{0.95} \\
\hline & SST & 0.10 & 0.20 & 0.8 & 0.21 & 0.19 & \\
\hline \multirow{2}{*}{ SW } & $T_{a}$ & 0.17 & 0.01 & 0.1 & -0.03 & 0.04 & \multirow{2}{*}{0.75} \\
\hline & SST & 0.04 & -0.02 & -0.1 & -0.02 & -0.02 & \\
\hline \multirow{2}{*}{ C } & $T_{a}$ & 0.12 & 0.05 & 0.2 & 0.04 & 0.07 & \multirow{2}{*}{0.84} \\
\hline & SST & 0.08 & 0.01 & 0.0 & 0.05 & -0.04 & \\
\hline \multirow{2}{*}{ E } & $T_{a}$ & 0.00 & 0.00 & 0.0 & -0.04 & 0.04 & \multirow[b]{2}{*}{0.83} \\
\hline & SST & 0.01 & -0.02 & 0.0 & 0.05 & -0.04 & \\
\hline \multirow{2}{*}{ Entire water area } & $T_{a}$ & 0.04 & 0.06 & 0.3 & -0.03 & 0.09 & \multirow{2}{*}{0.80} \\
\hline & SST & 0.02 & 0.04 & 0.2 & 0.06 & 0.03 & \\
\hline
\end{tabular}

$\mathrm{N}$ o t e. $\sigma^{2}$ is dispersion; $b$ is the slope coefficient of the linear trend, ${ }^{\circ} \mathrm{C}$ for 10 years; $t r$ is the 40 -year trend, ${ }^{\circ} \mathrm{C} ; b_{w}, b_{c}$ are the $b$ values for the warm and cold seasons; $R$ is the correlation coefficient of the average annual SST and $T_{a}$. Here and in Table 2, the statistically significant (95\%) estimates of the trends and correlation coefficients are highlighted in bold.
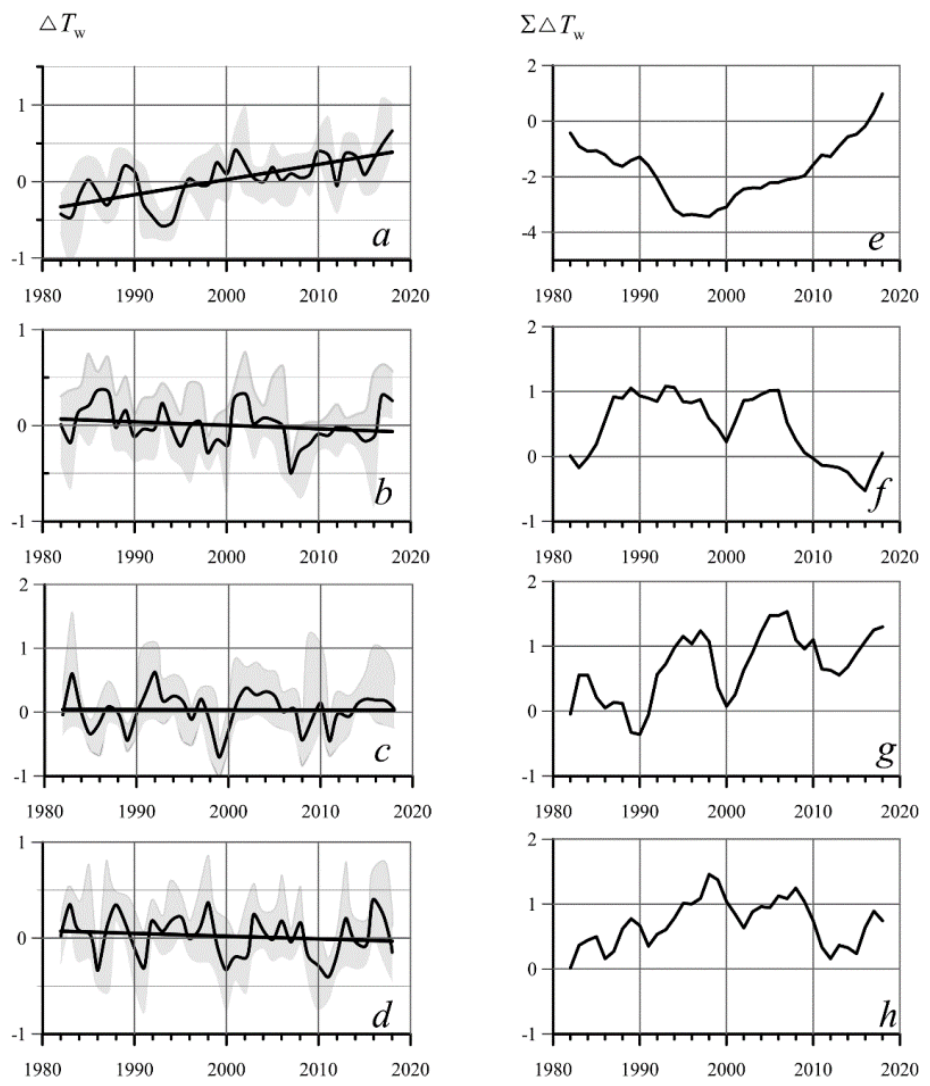

F i g. 2. Interannual variability of the annual average SST anomalies $\left(\Delta T_{w}\right)$ and cumulative anomalies $\Sigma \Delta T_{w}$ in the identified domains: NW $(a, e)$; SW $(b, f)$; C $(c, g)$; E $(d, h)$. The range of intra-year fluctuations, mean values over the region and linear trend (bold lines) are shown 
Integral curves of accumulated anomalies correspond to separate phases of alternation of warm and cold periods, consistent with changes in regional CIs and the AAC state. Differences in the position of individual extrema on the curves (Fig. 2) emphasize the inhomogeneous nature of these relationships and the warming process in space and time. For example, the temporal variations of the accumulated SST anomalies in the NW region (Fig. 2, e) correspond to the temporal variations of the accumulated anomalies in the SOI index and pressure at the center of the AVM (Australian minimum), the fluctuations of which are also closely related $(\mathrm{R}=-0.9)$. In this case, the accumulation of temperature anomalies of different signs in some regions occurs in antiphase (Fig. 2, $e, f$ ) - in accordance with the sign of the temperature trend. In $\mathrm{C}$ and $\mathrm{E}$ regions, a quasi-ten-year cyclicity of fluctuations is well expressed (Fig. 2, g, 2, h). It is caused by interannual variations in circulation anomalies in the Southern Hemisphere, changes in the SAM regime and long-range relations with ETM [21, 23, 42, 43].

To obtain generalized information on the structure of spatio-temporal changes in the SST and $T_{a}$ fields, the EOF of interannual fluctuations of the anomalies of these variables, as well as the anomalies of the geopotential field of the $500 \mathrm{hPa}$ isobaric surface $\left(\Delta \mathrm{H}_{500}\right)$ in the middle troposphere, were calculated. Field anomalies $\Delta \mathrm{H}_{500}$ were calculated for the latitudinal belt $0-80^{\circ} \mathrm{S}$. In Fig. 3, the spatial distribution of the obtained EOFs is presented in the form of fields of the correlation coefficients between the principal components, or the temporal coefficients of the field expansion in terms of the EOF (K), and the series of these parameters at each point, which permits to represent the gradations of the fields in a single scale and evaluate the value of the contribution of variability temperature in the principal components [44]. The fields of the correlation coefficients characterize the antiphase oscillations of the $T_{a}$, SST and $H_{500}$ anomalies, parameterized by different EOF modes. The main features of the spatio-temporal variability of the main energy-carrying modes $\left(C_{1}, C_{2}\right.$ and $\left.C_{3}\right)$ of SST and $T_{a}$ (Fig. 3, $a-c, d-f$ ) are similar (the correlation coefficient between the corresponding principal components is 0.9).

The first three EOF modes of $T_{a}$ and SST anomalies describe $\sim 60 \%$ of the contribution of these quantities' fluctuations to the total dispersion of the air and water temperature fields in both warm and cold seasons, and the corresponding EOF modes $\Delta H_{500}$ describe $\sim 70 \%$ of the geopotential field variability. The first oscillation mode of the geopotential (36\%) reflects the dominant circular regime of extratropical pressure field variability, as well as the currents, SST and zonal winds in the Southern Hemisphere [16] and is associated with the main AAC state (no data available). Position of the maxima of the expansion coefficients of the second and third modes (Fig. 3, h, i) approximately corresponds to the South Pacific maximum and minimum location [12]. The main features of the spatial distribution of the expansion coefficients of the first modes $C_{1}$ of the EOF anomalies of $T_{a}$, SST and $\Delta H_{500}$ (Fig. $3, a, d, g$ ) are consistent with the distribution of the trend values of these climatic variables (Fig. 1, $a, b$ ), and the values of the SST trend contribution and the first mode C1 of the SST EOF in the total dispersion of water temperature over the region are close $(\sim 30 \%)$. 


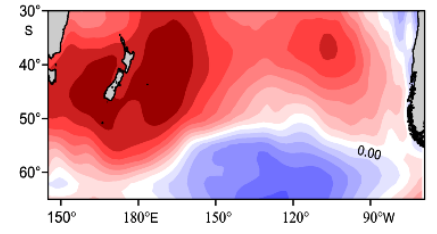

a

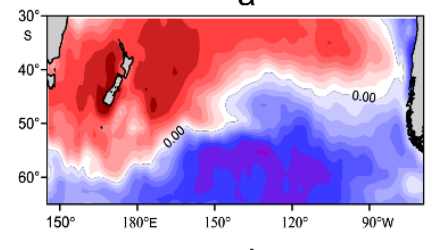

$d$

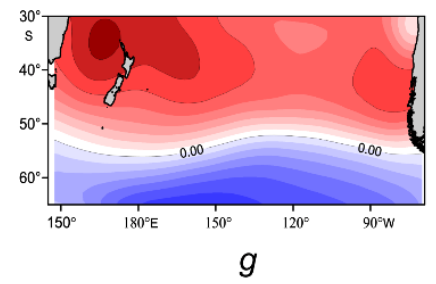

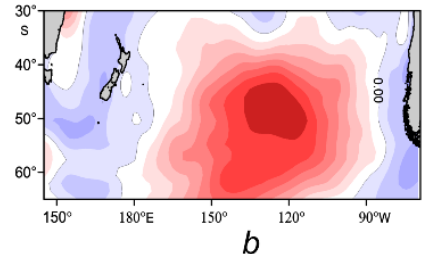

$b$

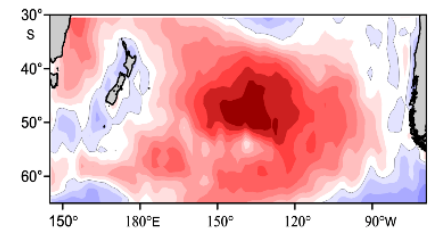

e
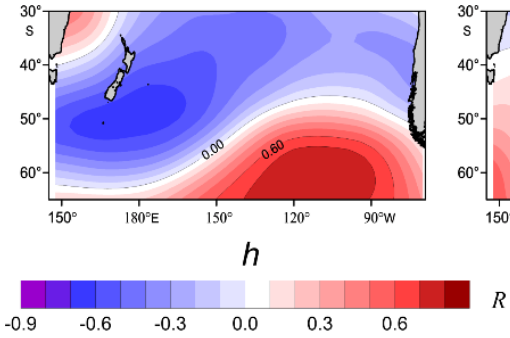
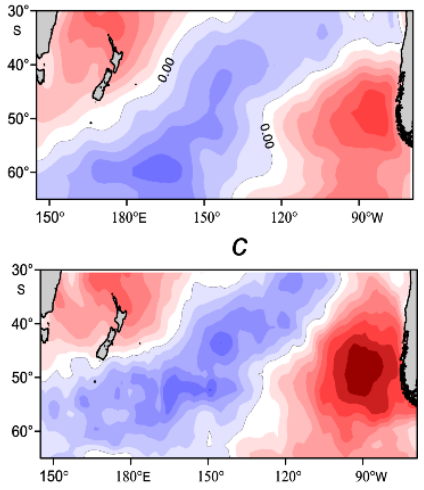

$f$

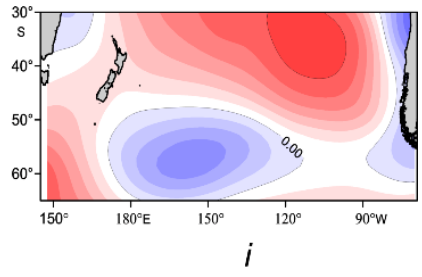

$R$

F i g. 3. Fields of the first, second and third EOF modes of the $T_{a}(a, b, c)$, SST $(d, e, f)$ and $H_{500}(g, h, i)$ anomalies based on the annual average data

\section{Temperature variability of the subsurface and intermediate layers}

Persistent energy imbalance in the upper atmosphere, defined from satellite measurements, indicates that the Earth's climate system continues to accumulate "excess heat" [1, 7]. Its input and accumulation in the ocean during global warming leads to the formation of extensive areas of temperature anomalies on its surface and is accompanied by the processes of heat redistribution in the atmosphere and the water column due to vertical mixing and horizontal advection. Changes in the heat content of the upper layer of the ocean can be explained mainly by either changes in the air-sea heat fluxes, or by horizontal heat advection in the ocean [9]. An important feature of water stratification in the area of the South Pacific subtropical gyre, bordering the ACC in the south [7], which, in combination with strong winds, contributes to the excess heat transfer from the surface to the depths due to isopycnic exchange processes, is the slope of isopycnic surfaces. Isopycnals of $26.5-27 \mathrm{~kg} / \mathrm{m}^{3}$, which come to the surface in the region of $50-60^{\circ} \mathrm{S}$ in the band of the southern and subarctic frontal zones, can descend to a depth of $>600 \mathrm{~m}$ at $40^{\circ} \mathrm{S}$, providing a kind of channel for the meridional transfer of heat and other indicators from the surface to the intermediate layers of the ocean $[9,45]$. Earlier it was noted [7] that in 2005-2014 in the central part of the considered water area between $30^{\circ} \mathrm{S}$ and $50^{\circ} \mathrm{S}$ the deepening of isotherms was observed. It was associated with water column warming as a result of increased convergence at the southern polar front and accompanied by an increase in the volume of Antarctic intermediate waters with lower salinity.

By averaging the GODAS grid data within each of the selected areas, the longterm variation of water temperature at 31 horizons in the 5-950 m layer for each 620

PHYSICAL OCEANOGRAPHY VOL. 28 ISS. 6 (2021) 
month of the year in 2005-2020 was calculated. The curves of the vertical distribution of $T_{w}$, the range of its variability and the trend of temperature at different horizons were plotted (Fig. 4). At these depths, there are surface and intermediate structural zones (surface and intermediate layers and water masses with different properties) [45-47], the boundary between which is at a depth of $\sim$ 150-250 m, which approximately corresponds to the active layer depth.
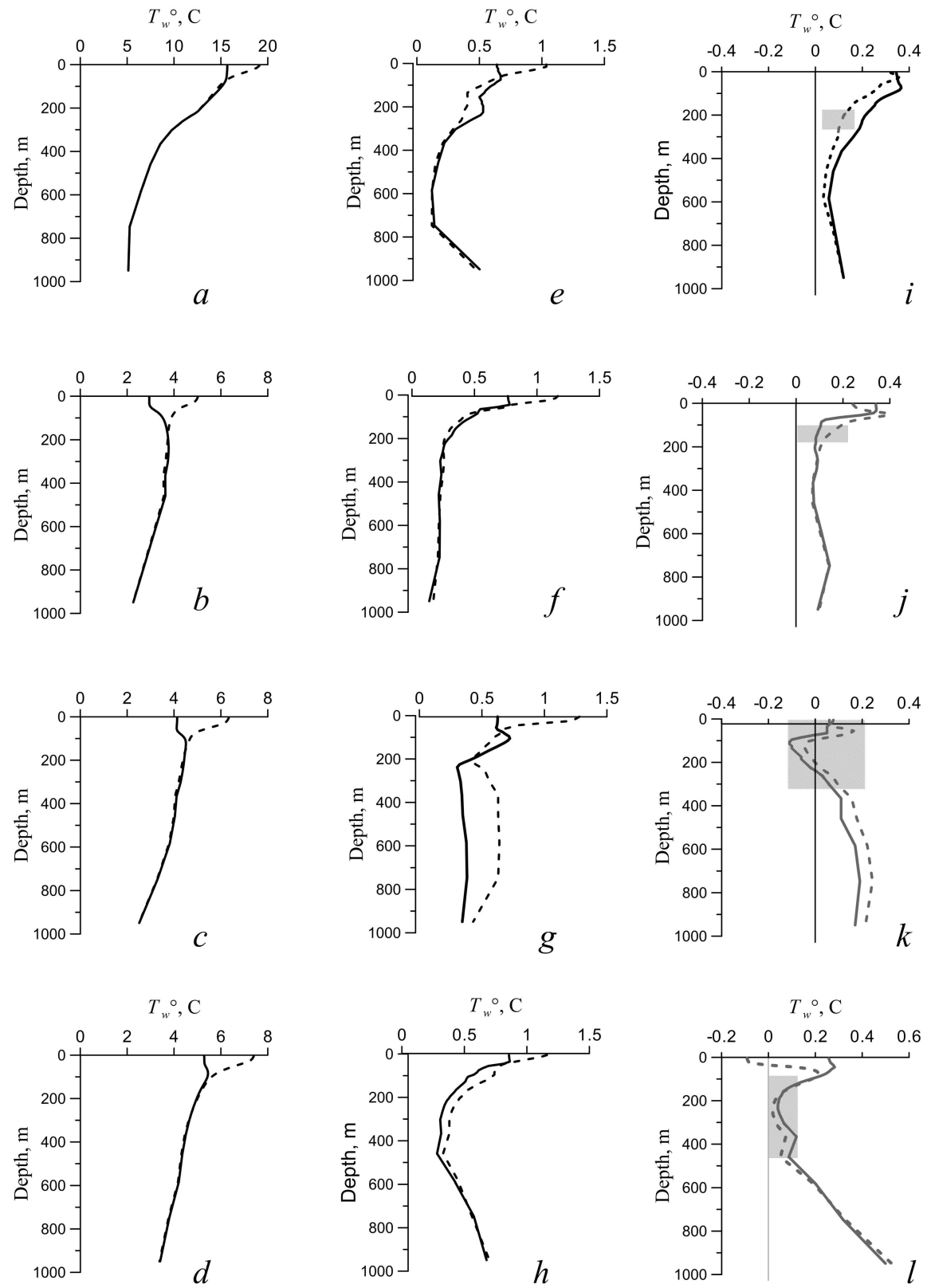

F i g. 4. Generalized curves of the vertical distribution $(a-d)$, the range of changes $(e-h)$ and the $T_{w}$ trend $(i-l)$ in the warm (dotted line) and cold (solid line) seasons, 2005-2020. From top to bottom: the NW, SW, C, E areas. The layers with the trend insignificant at the $95 \%$ level are shaded 
The range of seasonal variations in the average annual $T_{w}$ values at the nearsurface horizons in the $\mathrm{NW}$ region was $3.6^{\circ} \mathrm{C}$ and decreased to $2.1-2.2^{\circ} \mathrm{C}$ in other regions (Fig. 4, $a-d$ ). During each of the seasons it did not exceed $0.9-1.3^{\circ} \mathrm{C}$, reaching maximum values in the warm season within the active layer. Below the 100-200 $\mathrm{m}$ layer, the range of seasonal values varies with depth nonmonotonically (Fig. 4, $e-h$ ). In the area to the south of $59^{\circ} \mathrm{S}$ winter convective mixing destroys the stratification of the upper 400-600 $\mathrm{m}$ of the water column. In all areas, medium and strong correlations were found between temperature changes in surface and intermediate waters, propagating well below the active layer beyond the atmospheric influence, which is consistent with the results of instrumental observations [48] and is manifested in the vertical profiles of trends in $T_{w}$ (Fig. 4, $i-l$ ). For all selected areas, the sign and magnitude of temperature trends in individual layers of the water column in the warm and cold seasons change synchronously, and the predominant trend is the warming of the entire water column. The results obtained reflect only general trends and characteristics of interannual $T_{w}$ changes in the studied water area in the selected time period, under the assumption that the studied GODAS fields correspond to real conditions. At the same time, they are comparable with similar estimates obtained on the basis of generalizing observational data on the sections carried out in certain years of the period under study [7, 9, 34, 48]. Fig. 1, c, e shows maps of spatio-temporal variability of water temperature trends at individual horizons, and Fig. 5 - on meridional sections along $90^{\circ} \mathrm{W}$ and $170^{\circ} \mathrm{W}$ and zonal section along $45^{\circ} \mathrm{S}$, plotted according to GODAS data. The location of the meridional sections (Fig. 1, $d$ ) roughly corresponds to the position of the southern part of the P15 and P18 WOCE sections [34]. On the above maps and sections, areas with positive trend values are traced at different depths and in different parts of the water column.

The results obtained made it possible to clarify some details of the vertical profile of the temperature trend associated with trends in the dynamics of water and heat fluxes on the sea surface, internal processes causing the movement and deepening of isotherms, warming or cooling in certain regions. These processes, having complex and ambiguous causal relationships, were the subject of targeted field studies and modeling [38, 39, 49]. The role of the Southern Ocean and the wind field in the process of warming or cooling of intermediate waters propagating in the Pacific Ocean north of the ACC is noted. It should be understood in the context of dynamic balance, but not just local effects [16, 37]. The last 30 years have seen the SAM strengthening and the AAO index transition to the area of positive values. At the same time, both an increase and a shift to the south of subpolar western winds belt of the Southern Hemisphere, a change in the mesoscale vortex activity of the wind field, an exacerbation of the thermodynamic effect on the sea surface, and an increase in the volume of subduction of the subantarctic modal and Antarctic intermediate waters propagating northward from the subantarctic and south polar fronts [11, 38, 39]. Wind impact, as well as ice dynamics and thermodynamic effects of ice processes in the frontal zones have 
a significant effect on the formation and propagation of temperature anomalies in the water column and the properties of regional water masses [9, 50-52].
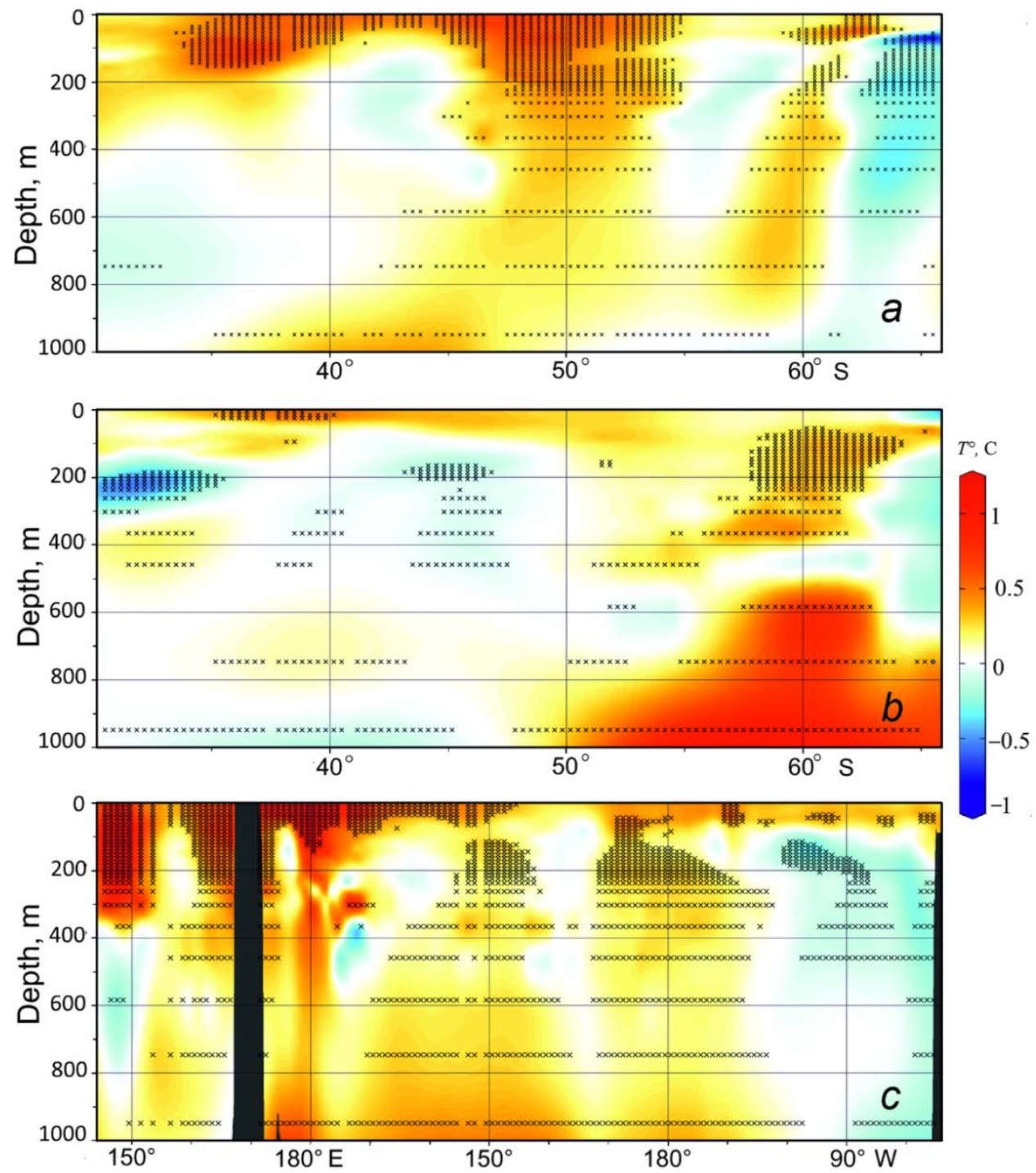

F i g. 5. Variability of the trends in the mean annual $T_{w}$ on the meridional $(a, b)$ and zonal $(c)$ sections, the location of which is shown in Fig. 1, $d$

Correlation between thermal conditions and atmospheric processes

A mutual correlation and regression analysis of variations in the time series of SST and $T_{w}$ anomalies and changes in the average monthly anomalies of the geopotential field of the $500 \mathrm{hPa}$ isobaric surface, atmospheric pressure in AAC and climatic indices characterizing the state and dynamics of the climate system in the considered regions was carried out. 
Statistically significant correlations between fluctuations of the main modes of the pressure field $\left(H_{500}\right.$ geopotential) in the middle troposphere with variations in water temperature are expressed in different seasons in all regions, except for the eastern one (no Table available). In this area, the temperature trends were the smallest (Table 1).

In the period under consideration, during the interannual fluctuations in atmospheric pressure in the AAC and the CI characteristics, there were trend components. Connectivity with them reflects the influence of various large-scale processes on the structure of the pressure and wind fields and thermal conditions of the region [33]. In the study area, the impact of these processes is manifested through the correlations of regional AAC (AVM, SPMA, SPMI, AM, AD) and CI of both hemispheres (AAO, PDO, PTW, SOI, NP, IPO, PNA, EP/NP) with the variability of SST and $T_{a}$ in the selected areas (Table 2, Fig. 6).

Table 2

Correlation coefficients of interannual fluctuations of the atmospheric pressure in the atmosphere action centers (AAC) and the climatic indices (CI) with the SST variations in the identified areas in the warm (w) and cold (c) seasons of the SH in 1982-2020

\begin{tabular}{|c|c|c|c|c|c|c|c|c|c|c|c|}
\hline \multirow{3}{*}{ Region } & \multicolumn{7}{|c|}{ AAC } & \multicolumn{4}{|c|}{ CI } \\
\hline & \multirow{2}{*}{$\frac{\mathrm{AVM}}{\mathrm{w}}$} & \multicolumn{2}{|c|}{ SPMA } & \multicolumn{2}{|c|}{ SPMI } & \multirow{2}{*}{$\frac{\mathrm{AM}}{\mathrm{C}}$} & \multirow{2}{*}{$\frac{\mathrm{AD}}{\mathrm{c}}$} & \multirow{2}{*}{$\frac{\mathrm{AAO}}{\mathrm{w}}$} & \multicolumn{2}{|c|}{ PDO } & \multirow{2}{*}{$\frac{\text { PTW }}{c}$} \\
\hline & & $\mathrm{w}$ & c & w & c & & & & $\mathrm{w}$ & c & \\
\hline NW & -0.5 & -0.1 & -0.1 & -0.2 & -0.4 & 0.5 & -0.4 & 0.4 & -0.2 & -0.4 & 0.5 \\
\hline SW & 0.3 & 0.1 & 0.4 & -0.1 & 0.1 & -0.4 & 0.4 & -0.4 & 0.3 & 0.1 & -0.4 \\
\hline C & 0.7 & 0.4 & 0.0 & 0.6 & 0.3 & -0.5 & 0.4 & -0.6 & 0.4 & 0.5 & -0.5 \\
\hline E & 0.2 & 0.1 & -0.1 & 0.0 & -0.3 & 0.0 & 0.2 & 0.3 & 0.3 & 0.4 & 0.0 \\
\hline
\end{tabular}

Spatial features and the nature of the corresponding relations are expressed in the spatial distribution field of both correlation and linear regression coefficients of fluctuations of various indices and variability of the SST and $T_{a}$ characteristics, reflecting the zone of their influence and impact on the thermal conditions of the region (Fig. 6).

When assessing the contribution of various CIs to trends in temperature and other independent climatic variables, it is necessary to take into account their seasonality, as well as the fact that interannual variations of individual CIs reflecting circulatory and climatic changes in the atmosphere and ocean are characterized by close direct or inverse correlations.

In the western half of the studied water area, in the last four decades, an increase in the eastern trade winds in the tropical zone associated with the phases 
of various CIs, as well as western winds in the region of $50-65^{\circ} \mathrm{S}$ adjacent to the ACC, were observed. According to our estimates, during this period in the region of $0-10^{\circ} \mathrm{S}, 160^{\circ} \mathrm{E}-160^{\circ} \mathrm{W}$ the average annual eastern point wind increased by $1.5 \mathrm{~m} / \mathrm{s}$, and the northern ones - by $0.4 \mathrm{~m} / \mathrm{s}$. At the same time, the flow rates of the western trade wind currents in the direction from east to west increase, which contributes to the formation of increased reserves of thermal energy in the western part of the equatorial-tropical zone [53], and AVM deepening - to the excess heat spread to the adjacent regions of the southern Pacific Ocean.
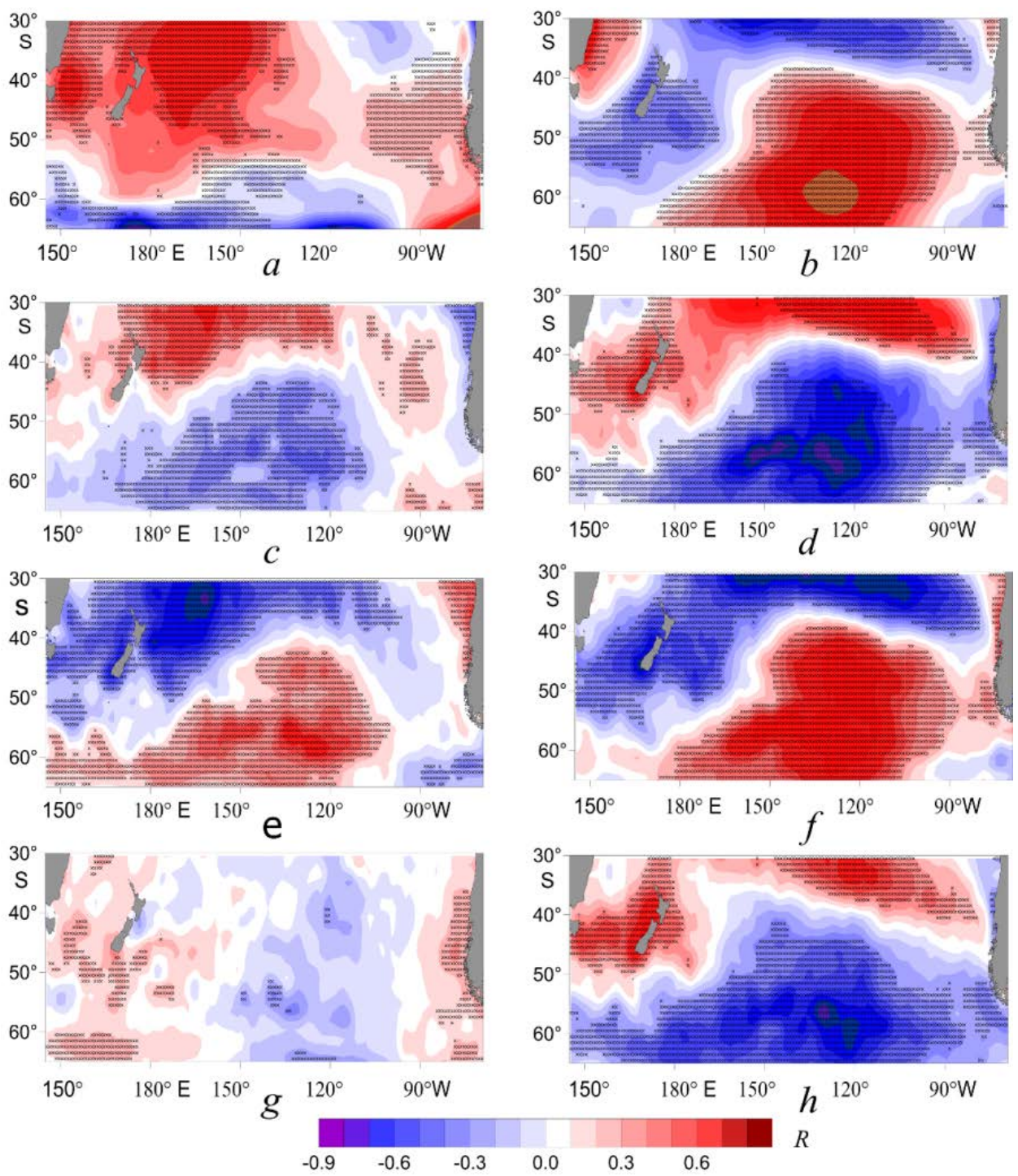

F i g. 6. Linear regression coefficients of the $T_{a}$ fluctuations with the $K_{1}$ EOF of $H_{500}$ geopotential anomalies in the warm $(a)$ and cold $(b)$ seasons. The same for the SST regression with the climatic indices: SOI $(c, d), I P O(e, f)$ and $A A O(g, h)$ 
In the south, in the region of $50-65^{\circ} \mathrm{S}, 160^{\circ} \mathrm{E}-160^{\circ} \mathrm{W}$ the average annual wind speed of the western points increased by $1.7 \mathrm{~m} / \mathrm{s}$, the northern - by $0.5 \mathrm{~m} / \mathrm{s}$. In the eastern part of the water area, to the west of $100^{\circ} \mathrm{W}$, an increase in the winds of the western and northern points was also observed. Similar changes in wind and thermal regimes, as well as an increase in the wind field vorticity and water circulation during the interaction of the equatorial-tropical (ENSO) and southern annular modes against the background of an increase in positive values of the Antarctic Oscillation Index (AAO), negative phase of the Interdecadal Pacific Oscillation (IPO) and the positive phase of the Pacific monsoon (PTW) were noted in different years [7, 16, 21]. They are an important source of climate change in the region on a 10-year scale [43]. The preliminary data analysis for 2005-2020 revealed statistically significant correlations between fluctuations in water temperature in individual layers of the water column with trends in individual CIs. So, in the NW region within the upper layer, these links are expressed with SOI and IPO indices in the cold season, with AMO in the warm season; in the upper layer in the SW region - with PNA during the warm period, in the intermediate layer - with the intensity of the Asian depression during the cold period; in the upper and intermediate layers in the $\mathrm{C}$ region - with the PDO, SOI, PTW, AAO indices in the cold period and PNA - in the warm period; in the upper layer in area E - with PDO in the cold season in the Southern Hemisphere. At the same time, the results obtained require further analysis and refinement using longer observation series, as well as with different time lags of correlations.

\section{Conclusion}

Both in the North and South Pacific Ocean, in the late 1970s a shift in the climate regime is expressed in the characteristics of interannual fluctuations of large-scale anomalies of meteorological and oceanographic parameters, the state of the atmosphere action centers, as well as indicators of heat and energy exchange between the ocean and the atmosphere. General trends of warming and their regional features in certain areas of the extratropical zone of the region's water area are considerably different. In the near-water layer of the atmosphere and on the sea surface, warming trends are expressed in positive trends in the $T_{a}$ and SST fields, mainly in the northwest of the region, where they are statistically significant and reach a maximum of $0.4-0.6^{\circ} \mathrm{C} / 10$ years in the Tasmanian Sea area and to the northeast of New Zealand Island. Water areas with minimal and negative or insignificant values of air and water temperature trends are located on the southern and eastern periphery of the studied water area - in the area of influence of cold currents. For the entire studied water area, the trends of the mean annual SST and $T_{a}$ were $\sim 0.04-0.06^{\circ} \mathrm{C} / 10$ years, which is $2-3$ times less than for the subarctic region of the northern Pacific Ocean. Separate phases of warm and cold periods alternation in the interannual temperature variation are consistent with changes in regional CI and AAC state and emphasize the heterogeneous nature of this process in space and time. 
The first three EOF modes of the $T_{a}$ and SST anomalies describe $60 \%$ of the contribution of the fluctuations of these quantities to the total dispersion of the temperature fields, and the corresponding EOF modes $\Delta H_{500}$ describe $70 \%$ of the geopotential field variability and are associated with the state of the main regional seasonal and permanent AACs.

The spatio-temporal variability features of water temperature trends at different horizons differ significantly from the characteristics of the SST trends. Transformation of the spatial distribution of trends occurs already within the upper 200-m layer, and deeper, the maximum values of this magnitude are observed in the southeastern part of the water area. According to the estimates averaged for each region, the maximum positive values of the $T_{w}$ trend $\left(\sim 0.3-0.4^{\circ} \mathrm{C} / 10\right.$ years $)$ in the surface layer were observed in the NW and SW regions and in the lower part of the intermediate layer - up to $0.5^{\circ} \mathrm{C} / 10$ years in the $\mathrm{E}$ area, and small negative - in the upper layer in the $\mathrm{C}$ and $\mathrm{E}$ areas.

The influence of various large-scale processes on the structure of the pressure and wind fields and thermal conditions of the region is manifested through the correlations of regional AAC and climatic indices (AAO, PDO, PTW, SOI, NP, IPO, PNA, EP/NP) of both hemispheres. The spatial features and the nature of the corresponding relationships are clearly expressed in the field of spatial distribution of both the correlation and linear regression coefficients of fluctuations of various indices and the variability of the SST and $T_{a}$ characteristics, reflecting the zone of their influence and impact on the thermal conditions of the region.

\section{REFERENCES}

1. WMO, 2021. State of the Global Climate 2020. Provisional report. WMO-No. 1264. Geneva: WMO, 54 p. Available at: https://library.wmo.int/doc_num.php?explnum_id=10618 [Accessed: 23 April 2021].

2. Balmaseda, M.A., Trenberth, K.E. and Källén, E., 2013. Distinctive Climate Signals in Reanalysis of Global Ocean Heat Content. Geophysical Research Letters, 40(9), pp. 17541759. doi:10.1002/grl.50382

3. Blunden, J. and Arndt, D.S., eds., 2020. State of the climate in 2019. Bulletin of the American Meteorological Society, 101(8), pp. S1-S429. doi:10.1175/2020BAMSStateoftheClimate.1

4. Desbruyères, D.G, Purkey, S., McDonagh, E.L., Johnson, G.C. and King, B.A., 2016. Deep and Abyssal Ocean Warming from 35 Years of Repeat Hydrography. Geophysical Research Letters, 43(19), pp. 10356-10365. doi:10.1002/2016GL070413

5. Levitus, S, Antonov, J.I., Boyer, T.P. and Stephens, C., 2000. Warming of the World Ocean. Science, 287(5461), pp. 2225-2229. doi:10.1126/science.287.5461.2225

6. Willis, J., Roemmich, D. and Cornuelle, B., 2004. Interannual Variability in Upper Ocean Heat Content, Temperature, and Thermosteric Expansion on Global Scales. Journal of Geophysical Research: Oceans, 109(C12), C12036. doi:10.1029/2003JC002260

7. Volkov, D.L., Lee, S.-K., Landerer, F.W. and Lumpkin, R., 2017. Decade-long Deep-ocean Warming Detected in the Subtropical South Pacific. Geophysical Research Letters, 44(2), pp. 927-936. doi:10.1002/2016GL071661

8. Wang, C., 2019. Three-ocean Interactions and Climate Variability: a Review and Perspective. Climate Dynamics, 53(7-8), pp. 5119-5136. doi:10.1007/s00382-019-04930-x 
9. Gille, S.T., 2008. Decadal-Scale Temperature Trends in the Southern Hemisphere Ocean. Journal of Climate, 21(18), pp. 4749-4765. doi:10.1175/2008JCLI2131.1

10. Russell, J.L., Dixon, K.W., Gnanadesikan, A., Stouffer, R.J. and Toggweiler, J.R., 2006. The Southern Hemisphere Westerlies in a Warming World: Propping Open the Door to the Deep Ocean. Journal of Climate, 19(24), pp. 6382-6390. doi:10.1175/JCLI3984.1

11. Marshall, G.J., 2003. Trends in the Southern Annular Mode from Observations and Reanalyses. Journal of Climate, 16(24), pp. 4134-4143. doi:10.1175/15200442(2003)016<4134:TITSAM>2.0.CO;2

12. Mokhov, I.I., Chernokulsky, A.V. and Osipov, A.M., 2020. Atmospheric Centers of Action in the Northern and Southern Hemispheres: Features and Variability. Russian Meteorology and Hydrology, 45(11), pp. 749-761. https://doi.org/10.3103/S1068373920110011

13. Malinin, V.N. and Gordeeva, S.M., 2009. Fishing Oceanology of South-east Pacific. Volume 1. Variability of Habitat Factors. Saint Petersburg: RGGMU Publishing House, 278 p. (in Russian).

14. Orsi, A.H., Whitworth III, T. and Nowlin Jr., W.D., 1995. On the Meridional Extent and Fronts of the Antarctic Circumpolar Current. Deep Sea Research Part I: Oceanographic Research Papers, 42(5), pp. 641-673. doi:10.1016/0967-0637(95)00021-W

15. Lim, E-P., Hendon, H.H., Hope, P., Chung, C., Delage, F. and McPhaden, M.J., 2019. Continuation of Tropical Pacific Ocean Temperature Trend May Weaken Extreme El Niño and Its Linkage to the Southern Annular Mode. Scientific Reports, 9, 17044. doi:10.1038/s41598-019-53371-3

16. Sen Gupta, A. and England, M.H., 2006. Coupled Ocean-Atmosphere-Ice Response to Variations in the Southern Annular Mode. Journal of Climate, 19(18), pp. 4457-4486. doi:10.1175/JCLI3843.1

17. Gong, D. and Wang, S., 1999. Definition of Antarctic Oscillation Index. Geophysical Research Letters, 26(4), pp. 459-462. doi:10.1029/1999GL900003

18. Karoly, D.J., 1989. Southern Hemisphere Circulation Features Associated with El NiñoSouthern Oscillation Events. Journal of Climate, 2(11), pp. 1239-1252. doi:10.1175/15200442(1989)002<1239:SHCFAW>2.0.CO;2

19. Voskresenskaya, E.N. and Marchukova, O.V., 2015. Qualitative Classification of the La Niña Events. Physical Oceanography, (3), pp. 14-24. doi:10.22449/1573-160X-2015-3-14-24

20. Herman, A., 2015. Trends and Variability of the Atmosphere-Ocean Turbulent Heat Flux in the Extratropical Southern Hemisphere. Scientific Reports, 5, 14900. doi:10.1038/srep14900

21. Yeo, S.R. and Kim, K.Y., 2015. Decadal Changes in the Southern Hemisphere Sea Surface Temperature in Association with El Niño-Southern Oscillation and Southern Annular Mode. Climate of Dynamics, 45(11-12), pp. 3227-3242. doi:10.1007/s00382-015-2535-z

22. Ciasto, L.M., Simpkins, G.R. and England, M.H., 2015. Teleconnections between Tropical Pacific SST Anomalies and Extratropical Southern Hemisphere Climate. Journal of Climate, 28(1), pp. 56-65. doi:10.1175/JCLI-D-14-00438.1

23. Yuan, X. and Yonekura, E., 2011. Decadal Variability in the Southern Hemisphere. Journal of Geophysical Research: Atmospheres, 116(D19), D19115. doi:10.1029/2011JD015673

24. Fogt, R.L. and Bromwich, D.H., 2006. Decadal Variability of the ENSO Teleconnection to the High-Latitude South Pacific Governed by Coupling with the Southern Annular Mode. Journal of Climate, 19(6), pp. 979-997. doi:10.1175/JCLI3671.1

25. Cai, W.J., Shi, G., Cowan, T., Bi, D. and Ribbe, J., 2005. The Response of the Southern Annular Mode, the East Australian Current, and the Southern Mid-latitude Ocean Circulation to Global Warming. Geophysical Research Letters, 32(23), L23706. doi:10.1029/2005GL024701 
26. Tauvale, L. and Tsuboki, K., 2019. Characteristics of Tropical Cyclones in the Southwest Pacific. Journal of the Meteorological Society of Japan. Ser. II, 97(3), pp. 711-731. doi:10.2151/jmsj.2019-042

27. Fan, T., Deser, C. and Schneider, D.P., 2014. Recent Antarctic Sea Ice Trends in the Context of Southern Ocean Surface Climate Variations since 1950. Geophysical Research Letters, 41(7), pp. 2419-2426. doi:10.1002/2014GL059239

28. Boyer, T.P., Baranova, O.K., Coleman, C., Garcia, H.E., Grodsky, A., Locarnini, R.A., Mishonov, A.V., Paver, C.R., Reagan, J.R. [et al.], 2018. World Ocean Database 2018. NOAA Atlas NESDIS 87. [online] Available at: https://www.ncei.noaa.gov/products/worldocean-database [Accessed: 23 April 2021].

29. Thomson, R.E. and Emery, W.J., 2014. Data Analysis Methods in Physical Oceanography. 3rd ed. Elsevier. 728 p. https://doi.org/10.1016/C2010-0-66362-0

30. Hosoda, S, Ohira, T. and Nakamura, T., 2008. A Monthly Mean Dataset of Global Oceanic Temperature and Salinity Derived from Argo Float Observations. JAMSTEC Report of Research and Develoment, 8, pp. 47-59. doi:10.5918/jamstecr.8.47

31. Abraham, J.P., Baringer, M., Bindoff, N.L., Boyer, T., Cheng, L.J., Church, J.A., Conroy, J.L., Domingues, C.M., Fasullo, J.T. [et al] , 2013. A Review of Global Ocean Temperature Observations: Implications for Ocean Heat Content Estimates and Climate Change. Reviews of Geophysics, 51(3), pp. 450-483. doi:10.1002/rog.20022

32. Garreaud, R.D. and Battisti, D.S., 1999. Interannual (ENSO) and Interdecadal (ENSO-like) Variability in the Southern Hemisphere Tropospheric Circulation. Journal of Climate, 12(7), pp. 2113-2123. https://doi.org/10.1175/1520-0442(1999)012<2113:IEAIEL > 2.0.CO;2

33. Rostov, I.D., Dmitrieva, E.V., Rudykh, N.I. and Vorontsov, A.A., 2020. Climatic Changes in Thermal Conditions of Marginal Seas in the Western Pacific. Russian Meteorology and Hydrology, 45(3), pp. 169-178. doi:10.3103/S1068373920030048

34. Talley, L.D., 2007. Hydrographic Atlas of the World Ocean Circulation Experiment (WOCE). Volume 2: Pacific Ocean. Southampton, U.K.: International WOCE Project Office, 326 p.

35. Bretherton, C.S., Widmann, M., Dymnikov, V.P., Wallace, J.M. and Blade, I., 1999. The Effective Number of Spatial Degrees of Freedom of a Time-Varying Field. Journal of

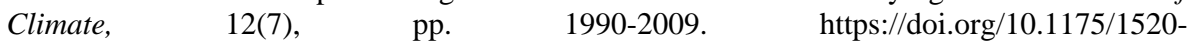
0442(1999)012<1990:TENOSD>2.0.CO;2

36. Li, Z., Holbrook, N.J., Zhang, X., Oliver, E.C.J. and Cougnon, E.A., 2020. Remote Forcing of Tasman Sea Marine Heatwaves. Journal of Climate, 33(12), pp. 5337-5354. doi:10.1175/JCLI-D-19-0641.1

37. Iudicone, D., Rodgers, K.B., Schopp, R. and Madec, G., 2007. An Exchange Window for the Injection of Antarctic Intermediate Water into the South Pacific. Journal of Physical Oceanography, 37(1), pp. 31-49. https://doi.org/10.1175/JPO2985.1

38. Liu, Ch., Wang, Zh., Li, B., Cheng, Ch. and Xia, R., 2017. On the Response of Subduction in the South Pacific to an Intensification of Westerlies and Heat Flux in an Eddy Permitting Ocean Model. Advances in Atmospheric Sciences, 34(4), pp. 521-531. doi:10.1007/s00376016-6021-2

39. Downes, S.M., Budnick, A.S., Sarmiento, J.L. and Farneti, R., 2011. Impacts of Wind Stress on the Antarctic Circumpolar Current Fronts and Associated Subduction. Geophysical Researches Letters, 38(11), L11605. doi:10.1029/2011GL047668

40. Rostov, I.D. and Dmitrieva, E.V., 2021. Regional Features of Interannual Variations in Water Temperature in the Subarctic Pacific. Russian Meteorology and Hydrology, 46(2), pp. 106114. doi:10.3103/S1068373921020059

41. Rostov, I.D., Dmitrieva, E.V. and Rudykh, N.I., 2021. Climatic Changes of Thermal Conditions in the Pacific Subarctic at the Modern Stage of Global Warming. Physical Oceanography, 28(2), pp. 149-164. doi:10.22449/1573-160X-2021-2-149-164 
42. Mo, K.C., 2000. Relationships between Low-Frequency Variability in the Southern Hemisphere and Sea Surface Temperature Anomalies. Journal of Climate, 13(20), pp. 35993610. doi:10.1175/1520-0442(2000)013<3599:RBLFVI>2.0.CO;2

43. Salinger, M.J., Renwick, J.A. and Mullan, A.B., 2001. Interdecadal Pacific Oscillation and South Pacific Climate. International Journal of Climatology, 21(14), pp. 1705-1721. doi:10.1002/joc.691

44. Popova, V.V., 2009. Modern Temperature Changes of Near Surface Air in the North of Eurasia: Regional Tendencies and Role of Atmospheric Circulation. Izvestiya RAN. Seriya Geograficheskaya, (6), pp. 59-69 (in Russian).

45. Kuksa, V.I., 1978. [Atlas of Intermediate and Subsurface Intermediate Waters of the World Ocean]. Moscow: Gidrometeoizdat, 83 p. (in Russian).

46. Stepanov, V.N., 1983. [Oceanosphere]. Moscow: Mysl, 270 p. (in Russian).

47. Koshlyakov, M.N. and Tarakanov, R.Yu., 2005. Intermediate Water Masses in the Southern Part of the Pacific Ocean. Oceanology, 45(4), pp. 455-473.

48. Sokolov, S. and Rintoul, S.R., 2003. Subsurface Structure of Interannual Temperature Anomalies in the Australian Sector of the Southern Ocean. Journal of Geophysical Researches: Oceans, 108(C9), 3285. doi:10.1029/2002JC001494

49. Iudicone, D., Madec, G. and McDougall, T.J., 2008. Water-Mass Transformations in a Neutral Density Framework and the Key Role of Light Penetration. Journal of Physical Oceanography, 38(7), pp. 1357-1376. doi:10.1175/2007JPO3464.1

50. Tamsitt, V., Cerovečki, I., Josey, S.A., Gille, S.T. and Schulz, E., 2020. Mooring Observations of Air-Sea Heat Fluxes in Two Subantarctic Mode Water Formation Regions. Journal of Climate, 33(7), pp. 2757-2777. doi:10.1175/jcli-d-19-0653.1

51. Cerovečki, I., Meijers, A., Mazloff, M., Gille, S., Tamsitt, V. and Holland, P., 2019. The Effects of Enhanced Sea Ice Export from the Ross Sea on Recent Cooling and Freshening of the Southeast Pacific. Journal of Climate, 32(7), pp. 2013-2035. doi:10.1175/jcli-d-18-0205.1

52. Haumann, F.A., Gruber, N. and Münnich, M., 2020. Sea-Ice Induced Southern Ocean Subsurface Warming and Surface Cooling in a Warming Climate. AGU Advances, 1(2), e2019AV000132. doi:10.1029/2019AV000132

53. Kidwell, A., Han, L., Jo, Y.-H. and Yan, X.-H., 2017. Decadal Western Pacific Warm Pool Variability: A Centroid and Heat Content Study. Scientific Reports, 7, 13141. doi:10.1038/s41598-017-13351-X

About the authors:

Igor D. Rostov, Head of the Informatics and Ocean Monitoring Laboratory, FSBSI V.I.Il'ichev Pacific Oceanological Institute, Far Eastern Branch, Russian Academy of Sciences (3 Baltiyskaya Street, Vladivostok, 690041, Russian Federation), Ph.D. (Geogr.), ORCID ID: 0000-0001-50817279, rostov@poi.dvo.ru

Elena V. Dmitrieva, Senior Research Associate, Informatics and Ocean Monitoring Laboratory, FSBSI V.I.Il'ichev Pacific Oceanological Institute, Far Eastern Branch, Russian Academy of Sciences (3 Baltiyskaya Street, Vladivostok, 690041, Russian Federation), Ph.D. (Techn. Sci.), ORCID ID: 0000-0002-0094-5296, e_dmitrieva@poi.dvo.ru

Natalya I. Rudykh, Senior Research Associate, Informatics and Ocean Monitoring Laboratory, FSBSI V.I.Il'ichev Pacific Oceanological Institute, Far Eastern Branch, Russian Academy of Sciences (3 Baltiyskaya Street, Vladivostok, 690041, Russian Federation), Ph.D. (Geogr.), ResearcherID: N-5821-2018, rudykh@poi.dvo.ru

Contribution of the co-authors:

Igor D. Rostov - development of the article structure, processing and analysis of the data, writing the article text 
Elena V. Dmitrieva - collection and preparation of initial data for reanalysis, calculations, drawing design, text editing

Natalya I. Rudykh - collection and processing of initial data on meteorological stations, calculations, editing of text and references

All the authors have read and approved the final manuscript.

The authors declare that they have no conflict of interest. 